\title{
Scatter Radiation Dose Assessment in the Radiology Department of Cape Coast Teaching Hospital-Ghana
}

\author{
J. Owusu-Banahene' ${ }^{1,2}$, E. O. Darko1,2, D. F. Charles ${ }^{1}$, A. Maruf ${ }^{1}$, I. Hanan ${ }^{3}$, G. Amoako ${ }^{3}$ \\ ${ }^{1}$ Radiation Protection Institute, Ghana Atomic Energy Commission, Accra, Ghana \\ ${ }^{2}$ Graduate School of Nuclear and Allied Sciences, University of Ghana, Legon, Atomic Campus, Kwabenya-Accra, Ghana \\ ${ }^{3}$ Department of Physics, College of Agriculture and Natural Sciences, University of Cape Coast, Cape Coast, Ghana \\ Email: *owusubanas@yahoo.com
}

How to cite this paper: Owusu-Banahene, J., Darko, E.O., Charles, D.F., Maruf, A., Hanan, I. and Amoako, G. (2018) Scatter Radiation Dose Assessment in the Radiology Department of Cape Coast Teaching Hospital-Ghana. Open Journal of Radiology, 8, 299-306.

https://doi.org/10.4236/ojrad.2018.84033

Received: September 5, 2018

Accepted: December 23, 2018

Published: December 26, 2018

Copyright $\odot 2018$ by authors and Scientific Research Publishing Inc. This work is licensed under the Creative Commons Attribution International License (CC BY 4.0).

http://creativecommons.org/licenses/by/4.0/

(c) (i) Open Access

\begin{abstract}
During the operation of an X-ray machine, if the radiation protection of X-ray room is insufficient, not only the patient but also clinical staffs as well as public are exposed to high X-ray exposures. In this research work, leakage and scattered radiations were measured from X-ray machine in the radiology department of Cape Coast Teaching hospital in the Cape Coast Municipality of Ghana. The scattered radiation exposures of X-rays in some selected areas within the facility were measured. The X-ray machine was operated for a range of kilo voltage peaks of $\mathrm{kV}_{\mathrm{p}} 77,70,63$ and 66 with intensities 20, 6.3 and $8.0 \mathrm{mAs}$, which represents the main technique factors of some body parts such as chest, lumbar spine and extremities during radiographic examinations. The measurements were performed using a RADOS-120 Universal survey meter. The radiation doses rates measured in the various locations in the Radiology Department of Cape Coast Teaching Hospital of Ghana were in the range of 0.10 $\mu \mathrm{Sv} / \mathrm{hr}$ to $0.12 \mu \mathrm{Sv} / \mathrm{hr}$. These values were all within the background measurement of $0.10 \mu \mathrm{Sv} / \mathrm{hr}$. Moreover, there were no risks of high radiation doses to patients, staffs and people visiting the X-ray department. The results obtained indicated that within the radiology department of the Hospital, all the selected locations were very safe to patients, occupational workers and the general public which could be attributed to adequate shielding in the facility.
\end{abstract}

\section{Keywords}

X-Rays, Exposure, Dose, Scattered and Leakage Radiation

\section{Introduction}

The German physicist Roentgen, while studying the properties of cathode rays in 
1885 , found that a very penetrating radiation was coming from a discharge tube. Since the nature of radiation was hitherto unknown, it was called X-rays. Subsequently, the properties of this radiation were thoroughly investigated and established but they are still known as X-rays. The discovery of new and unknown radiation stimulated the imagination of many workers who made serious attempts to establish its nature. On the basis of several experiments, it was recognized that most of the properties of this radiation are similar to those of electromagnetic waves of very short wavelengths. These radiations are produced mainly by machines when high voltage electrons interact with matter. X-rays are similar to gamma rays as they can pass through fairly thick materials. Ionization radiation has brought substantial benefits when used in medicine, but there are known risks due to stochastic effects and deterministic effects [1] [2] [3].

In radiology department of the hospital under investigation, three methods of patient dose assessment are used; these are 1) direct dose measurement on a patient, 2) dose measurements in physical phantom, and 3) Monte Carlo simulations. Lack of up-to-date dose information and conversion coefficient complicates the justification and optimization of the procedures. Choosing the best procedure for the diagnosis with the lowest radiation dose and cost proves to be challenging [4] [5].

Passive solid-state dosimeters can be used for direct dose measurement on a patient and in a phantom for a specific medical examination. The characteristics of the passive dosimeter are that the radiation induces ionization in the material, which is proportional to the energy absorbed in matter. Thermo luminescence dosimeter (TLD), optically stimulated luminescence dosimeter (OSLD), and Radiophoto luminescence Dosimeter (RPLD) are commonly used as passive dosimeters [6] [7] [8].

The longer a person is exposed to radiation, the more energy the body will be absorbed from the radiation. This is not to be mistaken with the idea that the radiation will somewhat stay in the body causing other health effects. The energy will immediately affect the body by breaking bonds in molecules or affecting the cells in the body. It is the absorption of energy that may lead to health effects. Any time radiation interacts with the body, it has the potential to damage the cells in the body, possibly leading to health effects. As more and more energy is transferred to the body by the radiation, the chances of causing a health effect also increases [9] [10].

\section{Method}

This research work has been carried out by the measurement of the effective dose rates due to scattered radiation from diagnostic X-ray room in Cape Coast Teaching Hospital, Cape Coast of Ghana. The radiation dose was monitored by using a portable survey meter called RADOS Universal Survey Meter RDS-120. The model of the fixed X-ray machine was Bucky Diagnost manufactured by Philips. The survey meter is equipped with an end window Geiger-Muller counter 
cylindrical tube enabled to detect different kinds of ionizing radiation such as gamma and X-rays. Therefore, it was suitable appropriate or good for this research work as it was able to measure the radiation doses or radiation exposure using X-rays. The survey meter was used to measure the effective dose or scattered X-rays at the control area (e.g. protected cubicle), and uncontrolled areas such as patient waiting area, Radiographer's office, changing room and just behind the main door of the diagnostic X-ray unit as shown in Figure 1.

Measurements were performed during the daytime, normal working hours of the selected hospital which was five hours, from 8 AM to 1 PM per day. Before the X-ray machine was switched on, the background radiation dose rate at the Radiology Department of the hospital was measured and found to be $0.10 \mu \mathrm{Sv} / \mathrm{h}$. Subsequently after the exposure to the radiation, the fall out radiation was measured in the control panel, radiographer's office, changing room, just behind the main door and patient waiting area. The X-ray machine was operated for a range of kilo-electron volts of 77, 70, 63 and 66 and intensities 20, 6.3 and 8.0 $\mathrm{mAs}$ which represent the exposures for diagnostic imaging of body parts such as chest, lumbar spine and extremities respectively. Above exposure ranges and

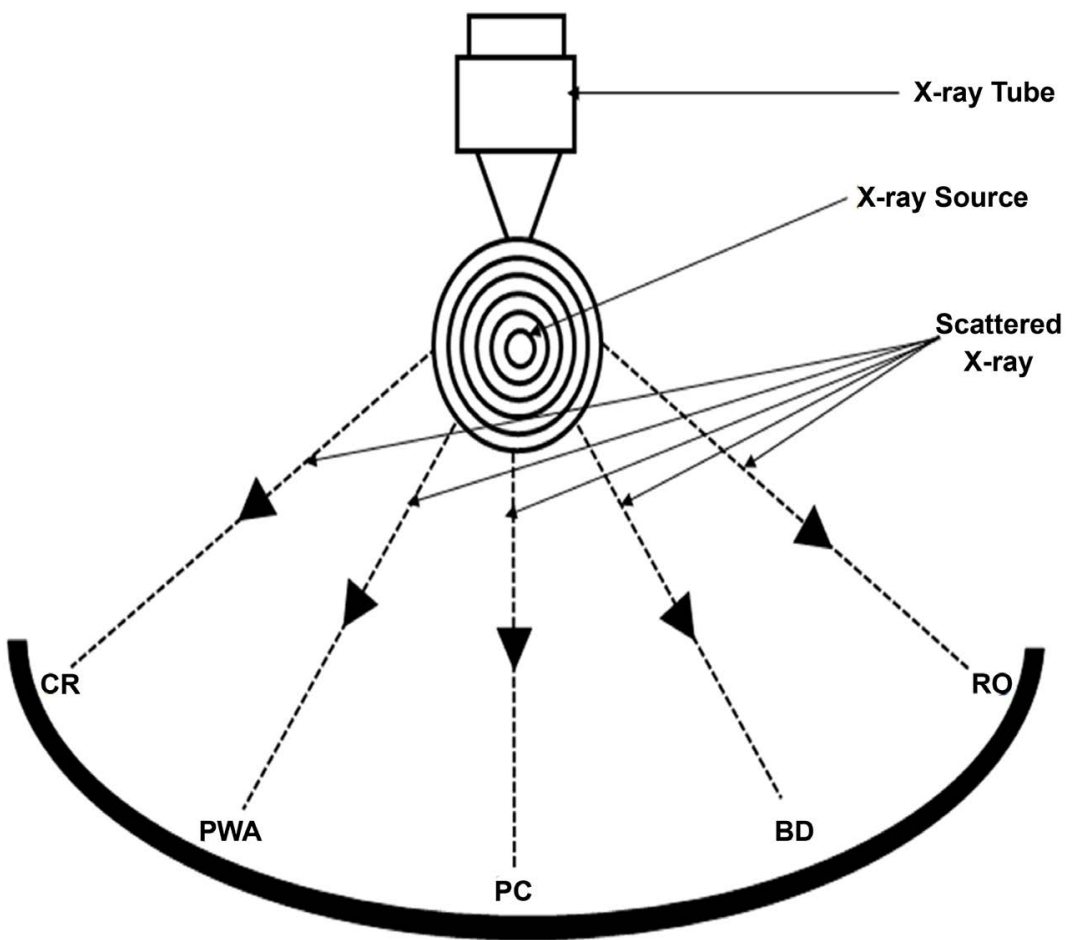

Figure 1. Schematic diagram of scattered X-rays at the Radiology department of Cape Coast Teaching Hospital. Legend: CR: Changing Room means a place where by patients have to remove their clothing's and put on hospital clothing for radiologic examination; PWA: Patient Waiting Area is an area whereby patients are allowed to sit or wait before they are called for X-rays examination; PC: Protected Cubicle is an area within the X-ray room where the radiographer stands or sits when X-rays are taken; BD: Behind Door is a lead-lined protected entrance door of an X-ray room; RO: Radiographer Office is a place or room outside the X-ray room whereby the radiographer sits to write notes of documents when $\mathrm{X}$-rays are not taken. 
types of imaging were selected because they were most mostly used at the selected areas of the hospital.

\section{Results and Discussion}

Before the measurements were done the background reading of the survey meter RADOS-120 was taken and it was found to be $0.1 \mu \mathrm{Sv} / \mathrm{h}$. At this energy $77 \mathrm{KeV}$ and $20 \mathrm{mAs}$, all dose rates were slightly above the background radiation. The patient waiting area and the radiographer's office have the least dose rates showing that these locations were the safest areas to be in when the X-ray machine is in operation. This is mainly due to the distance of these places from the X-ray machine as well as the design of the X-ray room. The protected cubicle, the changing room and just behind the main door have higher scatter radiation dose rates. This is also due to the closeness of these areas to the X-ray machine and probable some defects in the shielding provided to protect these areas. This means that some photons or X-rays penetrate through these locations but still these areas were safe due to adequate shielding provided at the facility as shown in Figure 2.

For this energy $66 \mathrm{KeV}$ and $20 \mathrm{mAs}$, there was no scatter radiation recorded in the radiographer's office and the patient waiting area. This is due to the lower energy of the X-rays used as well as adequate shielding in the room. The changing room, behind the main entrance door and the protected cubicle recorded a slightly higher reading than $0.1 \mu \mathrm{Sv} / \mathrm{h}$. This indicated that, all these areas are safe for both workers and patients as shown in Figure 3.

All radiation doses were within the acceptable range for this energy $70 \mathrm{KeV}$ and intensity $20 \mathrm{mAs}$ with no scatter radiation recorded in the patient waiting area. This showed that the patient waiting area is very safe for patients to sit whilst awaiting for examinations to be done. The changing room and the protected cubicle gave a higher radiation dose rate of $0.12 \mu \mathrm{Sv} / \mathrm{h}$ and $0.11 \mu \mathrm{Sv} / \mathrm{h}$ respectively. All locations were safe for both patients and workers as shown in Figure 4.

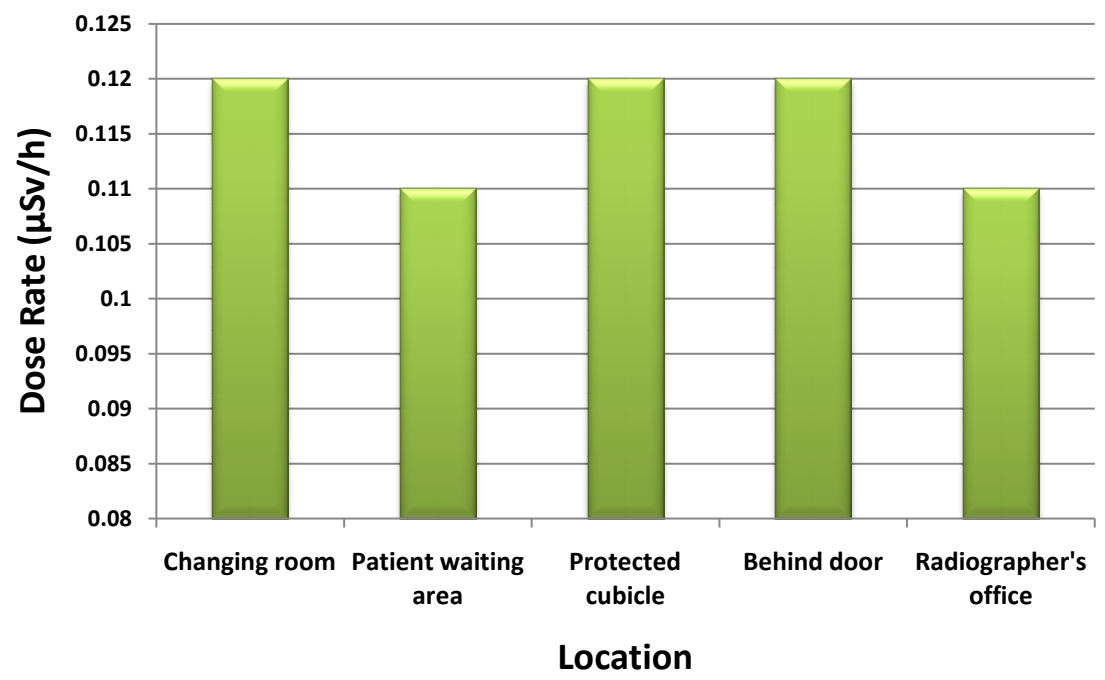

Figure 2. Variation of Dose Rate against Location for X-ray using $77 \mathrm{KeV}$ and $20 \mathrm{mAs}$. 


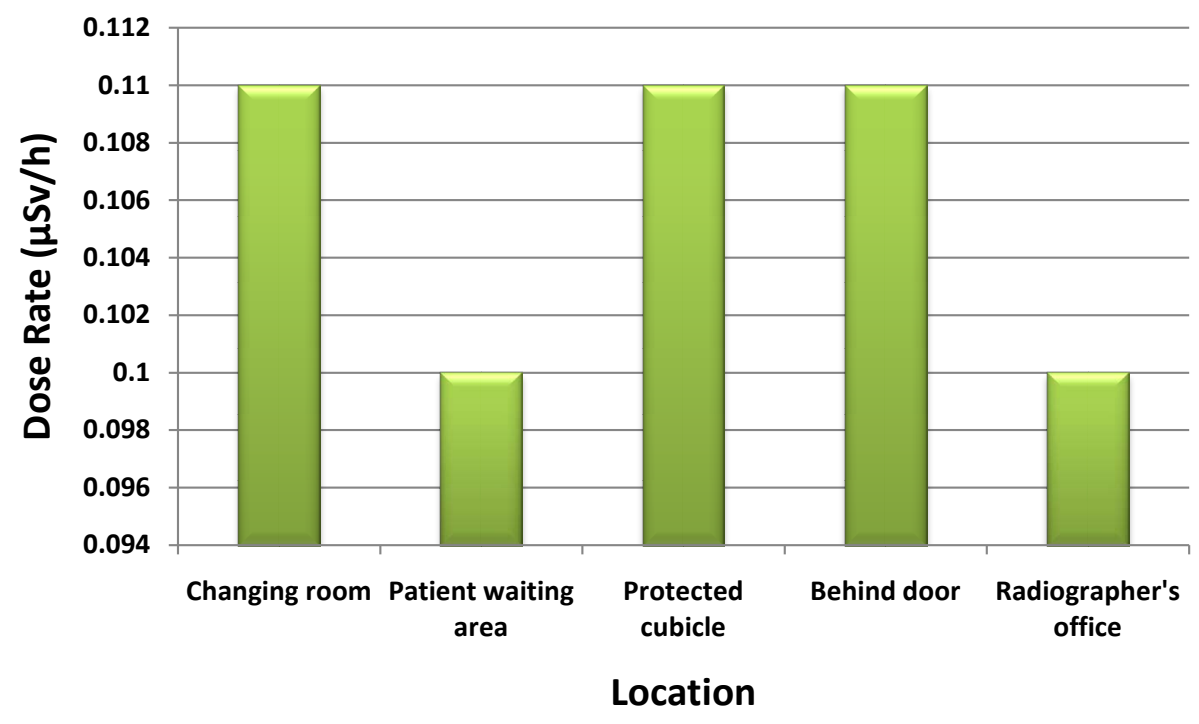

Figure 3. Variation of Dose Rate against Location for X-ray using $66 \mathrm{KeV}$ and $20 \mathrm{mAs}$.

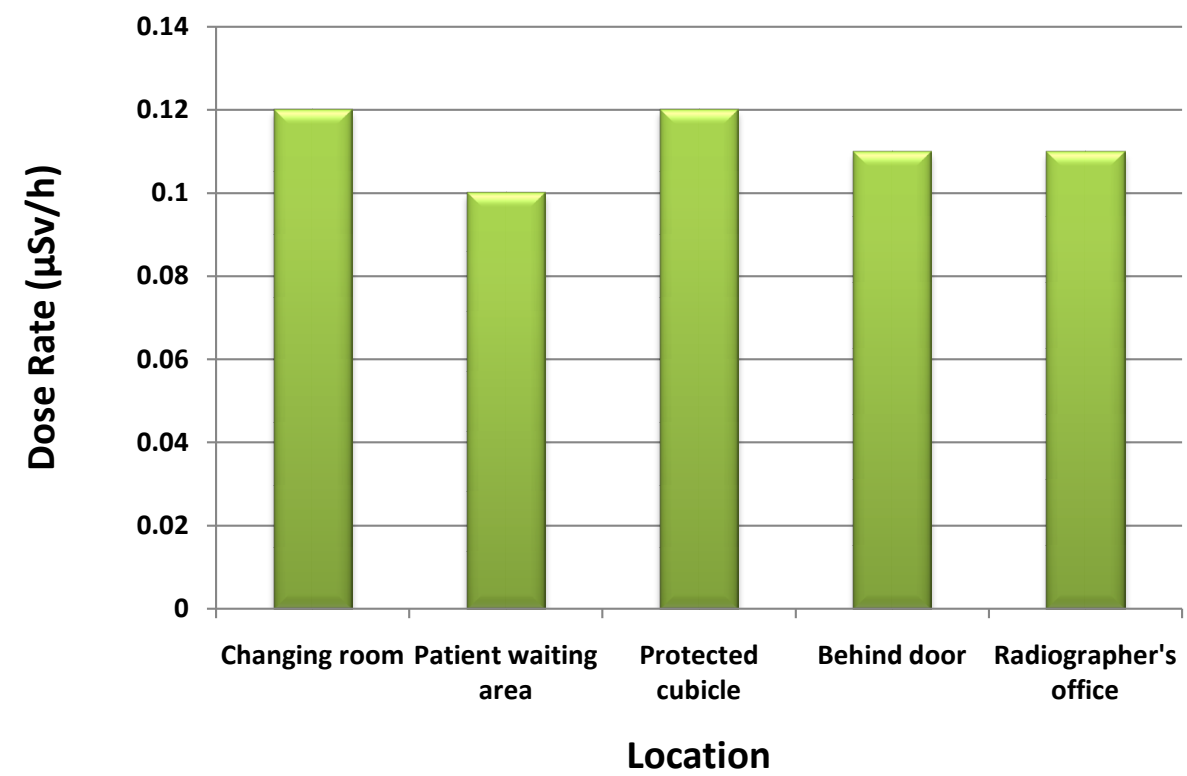

Figure 4. Variation of Dose Rate against Location for X-ray using $70 \mathrm{KeV}$ and $20 \mathrm{mAs}$.

At lower X-ray energies, the limiting value for the lower energy is for technique factors of $\mathrm{keV}$ of 66 and $20 \mathrm{mAs}$ where no radiation penetrated the shields into the locations. At $63 \mathrm{keV}$ and $20 \mathrm{mAs}$, very minimal radiation penetrated the changing room and the door whilst no scatter radiation was recorded in the patient waiting area, the protected cubicle and the Radiographer's office as shown in Figure 5. There was no scatter radiation recorded in any of the locations below this X-ray energy. This makes all these locations safe for both patients and workers when the $\mathrm{X}$-ray machine is under operation. Table 1 shows average effective dose rate with the various locations within the X-ray facility was duly observed and it was seen that the average effective dose rate for all the locations were almost equal to the background reading of $0.10 \mu \mathrm{Sv} / \mathrm{h}$. 


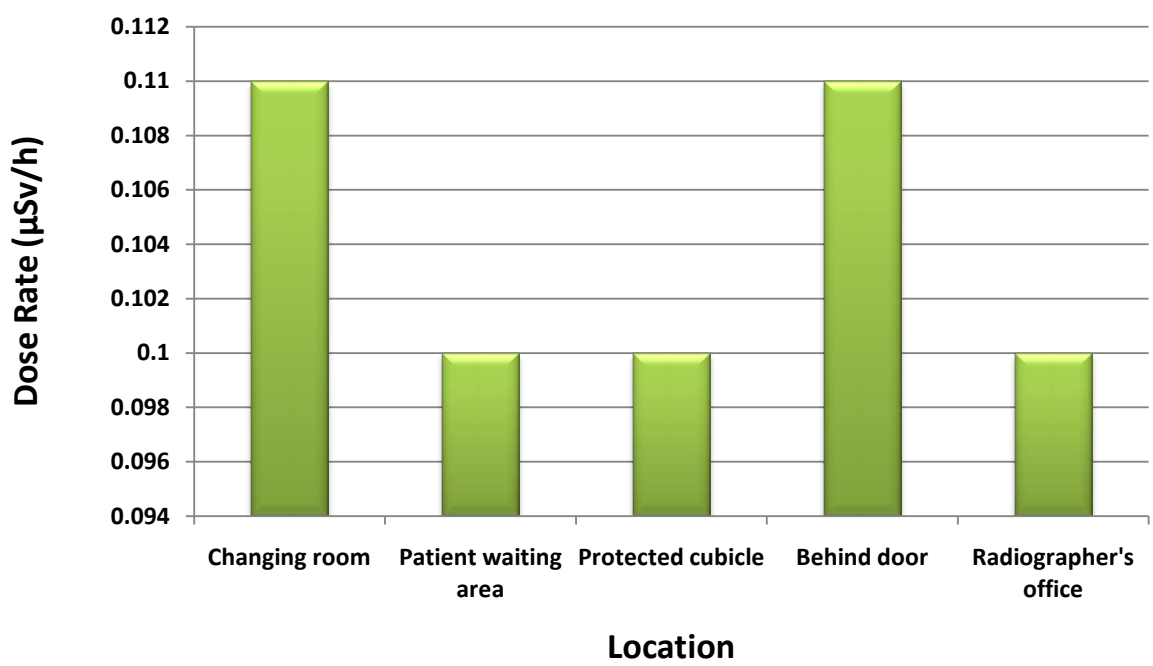

Figure 5. Variation of Dose Rate against Location for X-ray using $63 \mathrm{KeV}$ and $20 \mathrm{mAs}$.

Table 1. Results for each location with X-ray using $77 \mathrm{KeV}$ and $20 \mathrm{mAs}$.

\begin{tabular}{|c|c|c|c|c|}
\hline LOCATION & EFFE & OSE & (Sv/h) & $\begin{array}{c}\text { AVERAGE EFFECTIVE } \\
\text { DOSE RATE } /(\mu S v / h)\end{array}$ \\
\hline Changing room (CR) & 0.11 & 0.12 & 0.12 & 0.12 \\
\hline Patient waiting area (PWA) & 0.11 & 0.11 & 0.11 & 0.11 \\
\hline Protected cubicle (PC) & 0.12 & 0.12 & 0.13 & 0.12 \\
\hline Behind door (BD) & 0.11 & 0.12 & 0.12 & 0.12 \\
\hline Radiographer's office (RO) & 0.12 & 0.11 & 0.11 & 0.11 \\
\hline
\end{tabular}

The effective dose rates were measured in different locations such as the changing room, protected cubicle, patient waiting area, just behind the main door and the radiographer's office in selected hospitals in Cape Coast Municipality using a universal survey meter of RADOS-120. The results of the effective dose rate $(\mu \mathrm{Sv} / \mathrm{h})$ measurements for these areas are shown in Table 2 to Table 4. Dose rates were varying from one location to another depending on the distance of that location from the X-ray machine as shown in Figure 1. All measurements were with background radiation of $0.10 \mu \mathrm{Sv} / \mathrm{h}$. It can be shown that as the X-rays parameters $\mathrm{keV}$ and $\mathrm{m}$ As were increased more $\mathrm{X}$-rays are penetrated through these locations and were detected by the survey meter. Also, it can be seen that at lower X-ray energies, the effective doses were approximately the background radiation. This was observed in Figure 4. The effective dose rates measured at these locations were all below the reference dose rate of $0.1 \mathrm{mSv} / \mathrm{hr}$ and there were no adverse risks for public. This means that more photons or X-rays does not penetrate through Radiology Department rooms of the Hospital due to adequate shielding of the walls or doors. There is no obvious health risk of radiation exposure for all the exposed population visiting the Radiology Department of Cape Coast Teaching Hospital. 
Table 2. Results for each location with X-ray using $66 \mathrm{KeV}$ and $8.0 \mathrm{mAs}$.

\begin{tabular}{cllcc}
\hline LOCATION & \multicolumn{3}{l}{ EFFECTIVE DOSE RATE $/(\mu \mathrm{Sv} / \mathrm{h})$} & $\begin{array}{c}\text { AVERAGE EFFECTIVE } \\
\text { DOSE RATE } /(\mu \mathrm{Sv} / \mathrm{h})\end{array}$ \\
\hline Changing room (CR) & 0.12 & 0.11 & 0.11 & 0.11 \\
Patient waiting area (PWA) & 0.10 & 0.11 & 0.10 & 0.10 \\
Protected cubicle (PC) & 0.11 & 0.12 & 0.11 & 0.11 \\
Behind door (BD) & 0.11 & 0.11 & 0.11 & 0.11 \\
Radiographer's office (RO) & 0.10 & 0.11 & 0.10 & 0.10 \\
\hline
\end{tabular}

Table 3. Results for each location with X-ray using $70 \mathrm{KeV}$ and $20 \mathrm{mAs}$.

\begin{tabular}{ccccc}
\hline LOCATION & \multicolumn{3}{c}{ EFFECTIVE DOSE RATE/( $\mu \mathrm{Sv} / \mathrm{h})$} & $\begin{array}{c}\text { AVERAGE EFFECTIVE } \\
\text { DOSE RATE } /(\mu \mathrm{Sv} / \mathrm{h})\end{array}$ \\
\hline Changing room (CR) & 0.12 & 0.11 & 0.12 & 0.12 \\
Patient waiting area (PWA) & 0.10 & 0.10 & 0.11 & 0.10 \\
Protected cubicle (PC) & 0.12 & 0.12 & 0.11 & 0.12 \\
Behind door (BD) & 0.11 & 0.11 & 0.12 & 0.11 \\
Radiographer's office (RO) & 0.11 & 0.11 & 0.11 & 0.11 \\
\hline
\end{tabular}

Table 4. Results for each location with X-ray using $63 \mathrm{KeV}$ and $20 \mathrm{mAs}$.

\begin{tabular}{|c|c|c|c|c|}
\hline \multirow{2}{*}{$\begin{array}{c}\text { LOCATION } \\
\text { Changing room (CR) }\end{array}$} & \multicolumn{3}{|c|}{ EFFECTIVE DOSE RATE $/(\mu \mathrm{Sv} / \mathrm{h})$} & \multirow{2}{*}{$\begin{array}{c}\text { AVERAGE EFFECTIVE } \\
\text { DOSE RATE } /(\mu \mathrm{Sv} / \mathrm{h}) \\
0.11\end{array}$} \\
\hline & 0.11 & 0.10 & 0.11 & \\
\hline Patient waiting area (PWA) & 0.10 & 0.10 & 0.10 & 0.10 \\
\hline Protected cubicle (PC) & 0.10 & 0.10 & 0.11 & 0.10 \\
\hline Behind door (BD) & 0.10 & 0.11 & 0.11 & 0.11 \\
\hline Radiographer's office (RO) & 0.10 & 0.10 & 0.10 & 0.10 \\
\hline
\end{tabular}

\section{Conclusion}

The results indicated very small variations in the radiation doses as compared to the background radiation doses at the various locations at the radiology department of Cape Coast Teaching Hospital in Central Region of Ghana. This is probably due to different factors such as the distance of the locations from the $\mathrm{X}$-ray machine and the effectiveness of the barriers (e.g. walls and doors). Effective doses at the control area were always slightly higher than the effective doses at the radiographer's office by $0.01 \mu \mathrm{Sv} / \mathrm{h}$ for each X-ray energy. Nearer locations such as behind the entrance door, the changing room and the controlled areas had slightly higher effective dose rates than locations such as the Radiographer's office and the patient waiting area. Lower X-ray energies give rise to lower dose rates and the vice versa. From the results obtained, it was seen that all the hospital room barriers (e.g. doors and walls) were adequately shielded to reduce all radiation doses. Moreover, there are no risks of high radiation doses on the 
patients, staff and people visiting the X-ray department of Cape Coast Teaching Hospital. The results obtained indicate that within the radiology department of the Hospital, all the selected locations are very safe to patients, occupational workers and the general public. Finally it was observed that all the radiation protection principles were adequately observed.

\section{Acknowledgements}

The authors would like to acknowledge the Radiation Protection Institute of Ghana Atomic Energy and Radiology Department of Cape Coast Teaching Hospital for using their facilities during the research work.

\section{Conflicts of Interest}

The authors would like to declare that, there was no conflict of interest during this research work and the publishing of this article.

\section{References}

[1] Holmberg, O., Malone, J., Rehani, M., McLean, D. and Czarwinski, R. (2010) Current Issues and Actions in Radiation Protection of Patients. European Journal of Radiology, 76, 15-19. https://doi.org/10.1016/j.ejrad.2010.06.033

[2] ICRP (2007) International Commission on Radiological Protection Recommendations of the ICRP. Annals of the ICRP Publication 103, 37(2-4).

[3] ICRP (2012) International Commission on Radiological Protection, ICRP Statement on Tissue Reactions. Early and Late Effects of Radiation in Normal Tissues and Organs. Threshold Doses for Tissue Reactions in a Radiation Protection Context. Annals of the ICRP Publication 118, 41(1/2).

[4] Riesen, H. and Liu, Z. (Eds.) (2012) Optical Storage Phosphors and Materials for Ionizing Radiation, Current Topics in Ionizing Radiation Research. Mitsuru, N. (Ed.), InTech.

[5] UNSCEAR (2008) United Nations Scientific Committee on the Effects of Atomic Radiation. Sources and Effects of Ionizing Radiation, Report to the General Assembly Scientific Annexes A: Medical Radiation Exposures. UNSCEAR Vol. I.

[6] Bari, D.S., Amin, P.M. and Abdulkareem, N.A. (2015) Measurement of the Effective Dose Radiation at Radiology Departments of Some Hospitals in Duhok Governorate. Journal of Modern Physics, 6, 566-572. https://doi.org/10.4236/jmp.2015.65061

[7] Annor, M.N. (2012) Inventory Management in Ghana Health Service and Its Role in Health Care Delivery. Institute of Distance Learning, Kwame Nkrumah University of science and Technology, Kumasi, Ghana. KNUST.edu.gh

[8] Attix, F.H. (2004) Introduction to Radiological Physics and Radiation Dosimetry. Weinheim, Wiley-VCH.

[9] British Institute of Radiology/Institute of Physics and Engineering in Medicine (2000) Radiation Shielding for Diagnostic X-Rays. Report of a Joint BIR/IPEM Working Party, BIR, London.

[10] Daniel, O., Ogbanje, D. and Jonah, S.A. (2013) X-Ray and Scattering from Filters Used in Diagnostic Radiology. International Journal of Scientific and Research Publications, 3, Issue 7. 